\title{
Intracerebral Calcific Hydatic Cyst Mimicking Calcific Hematoma: A Case Report
}

\author{
N. D. A. Bankole ${ }^{1,2^{*}}$, M. Denou ${ }^{1,2}$, M. C. Sayore ${ }^{1,2}$, A. Melhaoui1,2, M. Boutarbouch ${ }^{1,2}$, \\ Y. Arkha' ${ }^{1,2}$, A. Elouahabi1,2, L. Rifi ${ }^{1,2}$ \\ ${ }^{1}$ Service de Neurochirurgie de l'Hôpital Des Spécialités Rabat, Morocco \\ ${ }^{2}$ Mohammed v University in Rabat, Rabat, Morocco \\ Email: ^bankolenouroudine@yahoo.fr, moussadenou@gmail.com, saymilena@gmail.com, adyl.melhaoui@gmail.com, \\ mahjouba.boutarbouch@gmail.com, yassernch@hotmail.com, elouahabi.a@hotmail.com, loubnarifi@hotmail.com
}

How to cite this paper: Bankole, N.D.A., Denou, M., Sayore, M.C., Melhaoui, A., Boutarbouch, M., Arkha, Y., Elouahabi, A. and Rifi, L. (2020) Intracerebral Calcific Hydatic Cyst Mimicking Calcific Hematoma: A Case Report. Yangtze Medicine, 4, 79-83.

https://doi.org/10.4236/ym.2020.41007

Received: June 4, 2019

Accepted: March 27, 2020

Published: March 30, 2020

Copyright (c) 2020 by author(s) and Scientific Research Publishing Inc. This work is licensed under the Creative Commons Attribution International License (CC BY 4.0).

http://creativecommons.org/licenses/by/4.0/ (c) (i) Open Access

\begin{abstract}
Introduction: Hydatid cyst intracranial is an endemic parasitosis and rare of the order of $1 \%$ to $4 \%$ of the cases. The calcified cerebral hydatid cyst is even more exceptional, we report a case collected in our service to illustrate the difficulties of diagnosis and the management. We will not discuss the outcome. Case Report: We reported a 22-year-old female which presented to right body, seizures of the type Bravais Jackson with facial participation, headache, dizziness, pre-critical and post critical seizures evolving over a month, and subsequently followed by a heaviness of the right hemi-body responsible for mowing when walking. She was hospitalized for management after performing a CT scan and brain MRI. The surgical treatment consisted of a left parietal flap with a complete excision of a process whose macroscopic appearance first evoked a calcified hydatid cyst confirmed by histology. Conclusion: The cerebral calcified hydatid cyst remains an exceptional pathology with some difficulties in diagnosis and management.
\end{abstract}

\section{Keywords}

Cyst Hydatid Calcific, Intracerebral Cyst, Hydatid Disease

\section{Introduction}

The cerebral localization of the hydatid cyst is rare in the order of $1 \%$ to $4 \%$ of the cases [1]. Hydatid disease (echinococcosis) is a worldwide zoonosis produced by the larval stage of the Echinococcus tapeworm [2]. In humans, the two main types of hydatid disease are caused by Echinococcus granulosus and Echinococcus multilocularis [3]. Calcification is very rare but seen more 
commonly in infestation with $E$. multilocularis [4]. Patients with intracranial hydatid cysts usually present with focal neurological deficit and features of raised intracranial pressure; and seizures. The treatment of hydatid cyst is surgical and the aim of surgery is to excise the cyst in totality without rupture to prevent recurrence or anaphylactic reaction [5]. The calcified cerebral hydatid cyst is even more exceptional and not often described in literature. However, we have to check all the other organs like liver and lung.

\section{Case Report}

It was a 22-year-old female patient with no history of pathology reported who presented Bravais Jackson right body seizures with facial involvement associated with headache and dizziness pre-critical and post critical evolving over a month, then subsequently a heaviness of the right hemi-body responsible for mowing when walking, she was hospitalized for management after performing a CT scan and brain MRI. Clinical examination found moderate raised intracranial pressure with right pyramidal syndrome. The cerebral CT was in favor of a calcified-wall chronic parietal left hematoma of $5 \mathrm{~cm}$, and MRI and Angio-MRI showed a left prerolandic parasagittal expansive process suggestive of either a glioma or a meningioma or a DNET (Figure 1 and Figure 2). The biological assessment was normal, the papilla exam of eyes showed papillary edema stage II. The Surgical treatment consisted of a left parietal bone flap arriving on the middle line and with a complete excision of a process whose macroscopic appearance first evoked a calcified hydatid cyst and confirmed by histology (Figure 3 and Figure 4).

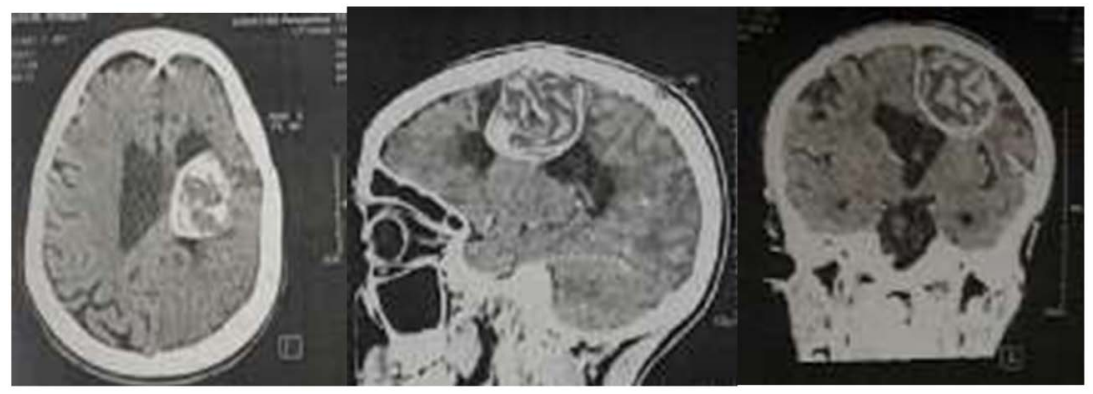

Figure 1. CT SCAN No injection Axial, sagital, coronal views: The cerebral CT was in favor of a calcified-wall chronic parietal left hematoma of $5 \mathrm{~cm}$.
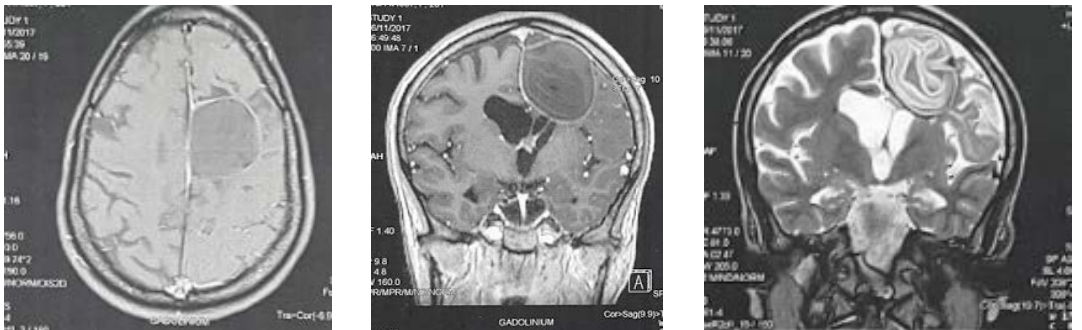

Figure 2. Left pre-rolandic parasagittal expansive process suggestive of either an glioma or meningioma or a DNET. MRI T1 Gado Axial and coronal view, T2 Coronal view. 

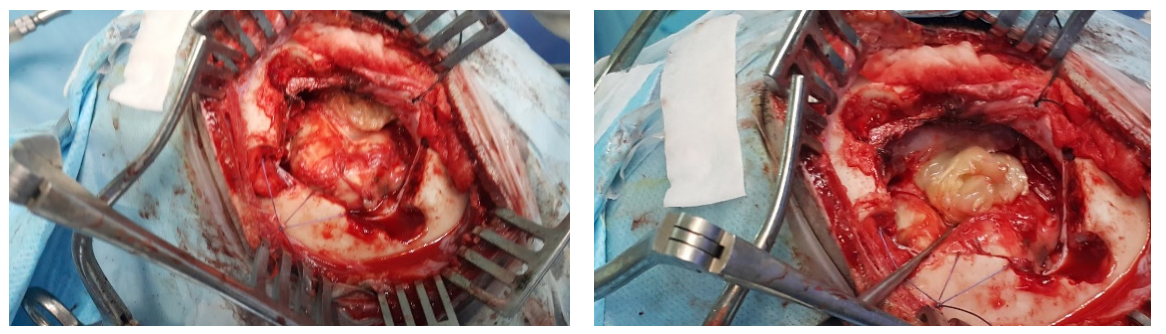

Figure 3. Bone Flap Arriving on midle line and perprocedure aspect of lesion who appearance evoked calciied cyst.

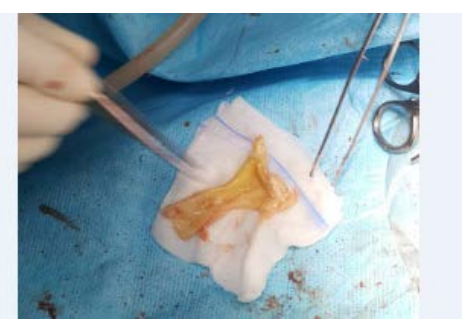

Figure 4. Cyst Hydatid calcified Mascrocopic view after excision.

\section{Discussion}

Hydatid disease is endemic pathology in our area here in Morocco. We found it in the Middle East, Mediterranean countries, South America, North Africa and Australia [6]. The liver (50\% - 77\%) and the lung (8.5\% - 43\%) are the organs most commonly involved [3]. Cerebral hydatid disease is rare (2\% of all hydatid infestations) and more common in pediatric population [2] [5]. Most of the cerebral hydatid cysts are supratentorial, usually located in the middle cerebral artery territory.

The parietal lobe is the most frequently involved region [6]. Our Patient come from North Africa and the cyst located in the Parietal lobe. Differential diagnosis includes tumors and infectious lesions such as tuberculosis and bacterial abscess. Because this infestation simulates sometimes malignancy by its invasive nature in the brain, gliomas and metastasis can also be included [3].

Different cystic lesions like porencephalic cyst, arachnoid cyst, cystic tumor of the brain and pyogenic abscess can also mimic echinococcosis [2]. As in our case which showed a left prerolandic parasagittal expansive process suggestive of either a glioma or a meningioma or a Dysembrioplastic neuroepithelial Tumors (DNET) [7] [8]. The treatment of hydatid cyst is surgical and the aim of surgery is to excise the cyst in totality without rupture to prevent recurrence or anaphylactic reaction [7] [9] [10]. All that showed how many it is very rare case and it is not easy to make diagnosis and ability to plan easily surgical management [11] [12]. Various surgical options, as summarized by Arana-Iniquez [13]. She includes puncture and aspiration of the cyst fluid through a small hole in the cyst wall, also she related cortical incision over cyst and expulsion of hydatid cyst by insufflation of air in the contralateral ventricle, and the most commonly done procedure designed to give birth to the intact cyst is by irrigating saline in the 
cyst wall-brain interface [13]. In our department we give birth of the hydatitic cyst intrcerebral but in this rare case that we suspected strongly on MRI we performed bone flap and cortisectomy to remove all the calcified cyst.

\section{Conclusion}

The cerebral calcified hydatid cyst remains an exceptional pathology and problematic of diagnostic and therapeutic difficulties; the histology confirms the diagnosis and allows to start the medical treatment after the surgery to prevent the recidive. When the cyst is calcificated, bone flap and excision are recommended to remove all the cysts. In Endemic Area we have to think about that front of unusual calcification on brain expansion if process.

\section{Conflicts of Interest}

The authors have not any conflict interest in this case report and any financial resources.

\section{References}

[1] Tyagi, D.K., Balasubramaniam, S. and Sawant, H.V. (2010) Primary Calcified Hydatid Cyst of the Brain. Journal of Neurosciences in Rural Practice, 1, 115-117. https://doi.org/10.4103/0976-3147.71729

[2] Andronikou, S., Welman, C.J. and Kader, E. (2002) Classic and Unusual Appearances of Hydatid Disease in Children. Pediatric Radiology, 32, 817-828. https://doi.org/10.1007/s00247-002-0785-5

[3] Biikte, Y., Kemanoglu, S., Nazaroglu, H., Ozkan, U., Ceviz, A. and Simsek, M. (2004) Cerebral Hydatid Disease: CT and MRI Findings. Swiss Medical Weekly, 134, 459-467.

[4] Senturk, S., Oguz, K.K., Soylemezoglu, F. and Inci, S. (2006) Cerebral Alveolar Echinococcosis Mimicking Primary Brain Tumor. American Journal of Neuroradiology, 27, 420-422.

[5] Dharker, S.R. (1996) Hydatid Disease. In: Ramamurthi, B. and Tandon, P.N., Eds., Text Book of Neurosurgery, 2nd Edition, Churchill Livingstone, New Delhi, 535-544.

[6] Onal, C., Orhan, B. and Metis, O. (1997) Three Unusual Cases of Intracranial Hydatid Cysts in Paediatric Age Group. Pediatric Neurosurgery, 26, 208-213. https://doi.org/10.1159/000121193

[7] Gupta, S., Desai, K. and Goel, A. (1999) Intracranial Hydatid Cyst: A Report of Five Cases and Review of Literature. Neurology India, 47, 214-217.

[8] Bresson-Hadni, S., Vuitton, D.A. and Bartholomot, B. (2000) A Twenty-Year History of Alveolar Echinococcosis: Analysis of a Series of 117 Patients from Eastern France. European Journal of Gastroenterology \& Hepatology, 12, 327-336. https://doi.org/10.1097/00042737-200012030-00011

[9] Algros, M.P., Majo, F. and Bresson-Hadni, S. (2003) Intracerebral Alveolar Echinococcosis. Infection, 31, 63-65. https://doi.org/10.1007/s15010-002-2178-y

[10] Kammerer, W.S. (1993) Echinococcosis Affecting the Central Nervous System. Seminars in Neurology, 13, 144-147. https://doi.org/10.1055/s-2008-1041118

[11] Ammann, R.W. and Eckert, J. (1996) Cestodes: Echinococcus. Gastroenterology 
Clinics of North America, 25, 655-689.

https://doi.org/10.1016/S0889-8553(05)70268-5

[12] Reitner, P., Szolar, D.H. and Schmid, M. (1996) Systemic Manifestations of Echinococcus alveolaris Infection. Journal of Computer Assisted Tomography, 6, 1030-1032. https://doi.org/10.1097/00004728-199611000-00033

[13] Iniquez, R.A. (1978) Echinococcus: Infection of the Nervous System. In: Vinken, P.J. and Bruyn, G.W., Eds., Hand Book of Clinical Neurology, Part 3, Elsevier/North Holland Biomedical Press, Amsterdam, 175-208.

\section{Abreviations}

DNET: Dysembrioblastic Neuroepithélial Tumor

MRI: Magnetic Resonnance Imaging 